\title{
Identification of pathogens for differential diagnosis of fever with jaundice in the Central African Republic: a retrospective assessment, 2008-2010
}

\author{
Christelle Luce Bobossi Gadia ${ }^{1}$, Alexandre Manirakiza ${ }^{2^{*}}$ (D), Gaspard Tekpa ${ }^{3}$, Xavier Konamna ${ }^{1}$, Ulrich Vickos ${ }^{1}$
} and Emmanuel Nakoune ${ }^{1}$

\begin{abstract}
Background: Febrile jaundice results clinically in generalized yellow coloration of the teguments and mucous membranes due to excess plasma bilirubin, accompanied by fever. Two types are found: conjugated and unconjugated bilirubin jaundice. Jaundice is a sign in several diseases due to viruses (viral hepatitis and arbovirus), parasites (malaria) and bacteria (leptospirosis). In the Central African Republic (CAR), only yellow fever is included on the list of diseases for surveillance. The aim of this study was to identify the other pathogens that can cause febrile jaundice, for better management of patients.
\end{abstract}

Methods: Between 2008 and 2010, 198 sera negative for yellow fever lgM were randomly selected from 2177 samples collected during yellow fever surveillance. Laboratory analyses targeted four groups of pathogens: hepatitis B, C, delta and E viruses; dengue, chikungunya, Zika, Crimean-Congo haemorrhagic fever, West Nile and Rift Valley arboviruses; malaria parasites; and bacteria (leptospirosis).

Results: Overall, 30.9\% sera were positive for hepatitis B, 20.2\% for hepatitis E, 12.3\% for hepatitis C and $8.2 \%$ for malaria. The majority of positive sera (40.4\%) were from people aged 16-30 years. Co-infection with at least two of these pathogens was also found.

Conclusion: These findings suggest that a systematic investigation should be undertaken of infectious agents that cause febrile jaundice in the CAR.

Keywords: Febrile jaundice, Differential diagnosis, Central African Republic

\section{Background}

Febrile jaundice, a frequent symptom of certain infectious diseases, appears clinically as a generalized yellow coloration of the integuments and mucous membranes, due to excess plasma bilirubin, and is accompanied by fever $>37.5{ }^{\circ} \mathrm{C}$ in the morning and $38{ }^{\circ} \mathrm{C}$ in the evening. It may be due secondarily to the release of a pyrogenic substance or of haemoglobin into the blood due to haemolysis or to cholestasis, with a decrease or halt in biliary secretion of intra- or extra-hepatic origin [1-4].

\footnotetext{
* Correspondence: amanirak@yahoo.fr

${ }^{2}$ Institut Pasteur of Bangui, Epidemiology Service, PO Box 923, Bangui, Central African Republic

Full list of author information is available at the end of the article
}

In low- and middle-income countries, predominantly in sub-Saharan Africa, febrile jaundice usually occurs in the presence of parasitic infections (malaria, toxoplasmosis, schistosomiasis), bacterial infections (typhoid, typhus, borreliosis, leptospirosis) or viral infections (hepatitis and Lassa, Marburg, Ebola, Crimean-Congo and Hantaan viral haemorrhagic fevers, cytomegalovirus, mumps, measles, rubella and Coxackievirus) and is sometimes present in sickle-cell disease [3-11]. These infections are major public health problems in the region, and understanding of their local epidemiology could indicate differential diagnoses [12].

For over a decade, the World Health Organization (WHO) has conducted epidemiological surveillance for 
yellow fever in countries such as the Central African Republic (CAR). Operationally, any case of febrile jaundice is considered a suspected case of yellow fever and must be tested for yellow fever antigen (immunoglobulin M, IgM) in a qualified national laboratory. Samples that are negative for IgM suggest the involvement of other pathogens. In the CAR, 3220 suspected cases of yellow fever were reported to the reference laboratory for haemorrhagic fever at the Institut Pasteur of Bangui between 2007 and 2012; of these, 55 were positive [13]. We designed an exploratory study to identify the pathogens in the samples that were negative for yellow fever.

\section{Methods}

\section{Database and target population}

Data from nationwide serosurveillance for yellow fever between 1 January 2008 and 31 December 2010 were analysed retrospectively. The data are in the Epi Info database (Centers for Diseases Control and Prevention, Atlanta (GA), United States of America), which also contains information on the samples and sociodemographic data on the donors. The patients who gave samples met the WHO standard definition of suspected cases of yellow fever, i.e. any person with acute onset of fever and jaundice appearing within 14 days of onset of the first symptoms [14]. The samples consisted of 1$5 \mathrm{~mL}$ of venous blood drawn into dry tubes and transported in refrigerated sample carriers at $4-8{ }^{\circ} \mathrm{C}$ to the national reference laboratory at the Institut Pasteur of Bangui. The transport was ensured by trained focal points at CAR regional health facilities. The data obtained for each patient were: age, sex, location, symptoms (fever and jaundice or any sign of bleeding), history of vaccination against yellow fever, date of onset of symptoms and dates of blood sampling and transport to the laboratory. Serum was separated from each patient's blood sample within $24 \mathrm{~h}$ and tested for yellow fever virus-specific fever IgM by enzyme-linked immunosorbent assay (ELISA). Positive results with ELISA were confirmed by quantitative polymerase chain reaction (qPCR). The remaining serum samples were stored at $-20{ }^{\circ} \mathrm{C}$ at the Institut Pasteur of Bangui.

\section{Selection of samples and identification of pathogens}

As the purpose of this study was to differentiate yellow fever from other infections that present with similar features (acute fever and jaundice), only samples that were negative for yellow fever were selected. The codes of 2177 samples negative for yellow fever IgM were entered on an Excel spreadsheet from laboratory registers, and 198 samples were randomly selected for this study on the basis of the availability of testing reagents. The corresponding serum samples were identified in the storage freezer. Four groups of pathogens were targeted: hepatitis
B, C, delta and E viruses; dengue, chikungunya, Zika, Crimean-Congo haemorrhagic fever, West Nile and Rift Valley arboviruses; malaria parasites; and bacteria (leptospirosis). The appropriate laboratory technique was used to identify each pathogen.

ELISA was used to screen for hepatitis, with a Murex Diasorin kit for hepatitis B virus (to detect hepatitis B surface antigen), antigen detection of hepatitis delta (HD) virus and a Monolisa ${ }^{\mathrm{Tm}}$ HCV Ag-Ab ULTRA kit (Bio-Rad) for hepatitis C virus (HCV). Leptospira infection was diagnosed with the Panbio Leptospira IgM ELISA (Standard Diagnostics, Republic of Korea). The results were interpreted according to the manufacturers' recommendations. Hepatitis E (HEV), dengue (DENV), chikungunya (CHIKV), Zika virus (ZIKV), CrimeanCongo haemorrhagic fever (CCHFV), West Nile virus (WNV) and Rift Valley (RVFV) infections were detected by qPCR [15-22]. The sequences of primers and probes used to identify these viruses are presented in Table 1.

Malaria was diagnosed with Standard Diagnostics Bioline Ag-Pf and Ag-pan (Standard Diagnostics, Ref 05FK60, Republic of Korea), which contains antibodies targeting both PfHRP2 and lactate dehydrogenase specific to $P$. falciparum and other Plasmodium species (P. vivax, $P$. ovale and $P$. malariae).

\section{Data analysis}

Stata 11.0 software was used to calculate proportions of test results. The results were compared according to sociodemographic characteristics with the chi-2 test. Statistical significance was assessed at $P<0.05$.

\section{Results}

Evidence of infection with at least one pathogen was found in $49.0 \%$ of samples $(n=97)$. Males under 35 years of age were the most commonly infected, but the difference was not statistically significant $(P=0.567$ and 0.118 , respectively). Of the 131 samples, $66.2 \%$ were from Bangui, the capital of the CAR, and its surrounding area, Ombella M'Poko (Table 2).

The predominant pathogens were hepatitis B (51.5\%; 50/97), E (33.0\%; 32/97) and C viruses (20.6\%; 20/97). Co-infections were frequent, at a rate of $25.8 \%(25 / 97)$. Analyses for other pathogens (leptospira, DENV, CHIK and Zika, CCHV, WNV and RVFV) yielded negative results. The results for 16 patients showed co-infection with hepatitis B, E and C viruses (Table 3).

\section{Discussion}

Almost half the samples from patients presenting with fever and jaundice contained at least one infectious agent. Hepatitis B, C and E viruses were the most common pathogens identified in our samples; these infections are endemic in the CAR $[23,24]$. The prevalence 
Table 1 Primers and probes used to detect arbovirus and hepatitis E virus

\begin{tabular}{|c|c|}
\hline Primers and probes & Nucleic acid sequences of primers and probes \\
\hline \multicolumn{2}{|l|}{ qPCR Zika virus (ZIKV) } \\
\hline ZIKV forward & 5-nt9271AARTACACATACCARAACAAAgTggT9297-3' \\
\hline ZIKV reverse & 5' nt9352-TCCRCTCCCYCTYTggTCTTg-9373 -3' \\
\hline ZIKV probe & nt 9304-FAM-CTYAgACCAgCTgAAR-BBQ-9320 \\
\hline \multicolumn{2}{|c|}{ qPCR Dengue total (DENV 1-4 system) } \\
\hline DENT forward & 5'- AGGACYAGAGGTTAGAGGAGA - 3' \\
\hline DENT reverse & 5'- CGYTCTGTGCCTGGAWTGAT -3' \\
\hline DENT probe & FAM-ACAGCATATTGACGCTGGGARAGACC-TAMRA \\
\hline \multicolumn{2}{|c|}{ qPCR Dengue subtypes (DENV1, DENV2, DENV3) } \\
\hline DEN1 forward & 5' ATACCYCCAACAGCAGGAATT - 3' \\
\hline DEN1 reverse & 5' AGCATRAGGAGCATGGTCAC -3' \\
\hline DEN1 probe & $\begin{array}{l}\text { FAM-TTGGCTAGATGGRGCTCATTCAAGAAGAAT- } \\
\text { TAMRA }\end{array}$ \\
\hline DEN2 forward & 5' TGGACCGACAAAGACAGATTCTT 3' \\
\hline DEN2 reverse & 5' CGYCCYTGCAGCATTCCAA 3' \\
\hline DEN2 probe & FAM-CGCGAGAGAAACCGCGTGTCRACTGT-TAMRA \\
\hline DEN3 forward & 5' AAGACGGGAAAACCGTCTATCAA 3' \\
\hline DEN3 reverse & 5' TTGAGAATCTCTTCGCCAACTG 3' \\
\hline DEN3 probe & FAM-ATGCTGAAACGCGTGAGAAACCGTGT-TAMRA \\
\hline \multicolumn{2}{|c|}{ qPCR Chikungunya (CHIK) } \\
\hline CHIK forward & 5'- AAGCTYCGCGTCCTTTACCAAG - 3' \\
\hline CHIK reverse & 5'- CCAAATTGTCCYGGTCTTCCT -3' \\
\hline CHIK probe & FAM-CCAATGTCYTCMGCCTGGACACCTIT-TAMRA \\
\hline
\end{tabular}

qPCR Rift Valley fever virus (RVFV)

RVFV forward 5'- AAA ggA ACA ATg gAC TCT ggT CA - 3'

RVFV reverse $\quad$ 5'- CAC TTC TTA CTA CCA TTC CTC CAA T-3'

RVFV probe $\quad$ FAM-AAA gCT TTg ATA TCT CTC AgT gCC CCA A -TAMRA

qPCR West Nile virus (WNV)

$\begin{array}{ll}\text { WNV3p forward } & 5^{\prime} \text { Agg TTA gWg gAg ACC CCg T - 3' } \\ \text { WNV3p reverse } & \text { 5' ggT TgT gCA gAg CAg AAg ATC -3' } \\ \text { WNV3p probe } & \text { FAM-CGGTTCCGGCGGTGGTTCT-TAMRA }\end{array}$

Conventional PCR Crimean-Congo haemorrhagic fever virus (CCHFV)

$$
\begin{array}{ll}
\text { CCHFV forward } & 5^{\prime}-\text { TGGACACCTTCACAAACTC }-3^{\prime} \\
\text { CCHFV reverse } & 5^{\prime} \text { - GACAAATTCCCTGCACCA - } 3^{\prime}
\end{array}
$$

qPCR Hepatitis E virus (HEV)

$$
\begin{array}{ll}
\text { HEV forward } & \text { 5' GCCCGGTCAGCCGTCTGG }-3^{\prime} \\
\text { HEV reverse } & \text { 5'-CTGAGAATCAACCCGGTCAC - } 3^{\prime} \\
\text { HEV probe } & \text { FAM-CGGTTCCGGCGGTGGTTTCT-TAMRA }
\end{array}
$$

of hepatitis B virus infection was higher than that found previously in the CAR by Komas et al., at 10.6\% [25]; however, those authors collected samples from apparently healthy individuals, while we studied patients pre-

\begin{tabular}{|c|c|c|c|c|c|c|}
\hline \multirow[t]{2}{*}{ Characteristic } & & \multicolumn{2}{|c|}{$\begin{array}{l}\text { Any positive } \\
\text { result }\end{array}$} & \multicolumn{2}{|c|}{$\begin{array}{l}\text { Negative } \\
\text { result }\end{array}$} & \multirow[t]{2}{*}{$P$} \\
\hline & & No. & $\%$ & No. & $\%$ & \\
\hline \multirow[t]{4}{*}{ Age (years) } & $<15$ & 35 & 52.2 & 32 & 47.8 & 0.567 \\
\hline & $16-24$ & 24 & 52.2 & 22 & 47.8 & \\
\hline & $25-34$ & 21 & 50.0 & 21 & 50.0 & \\
\hline & $\geq 35$ & 17 & 39.5 & 26 & 60.5 & \\
\hline \multirow[t]{2}{*}{ Sex } & Male & 43 & 43.4 & 56 & 56.6 & 0.118 \\
\hline & Female & 54 & 54.5 & 45 & 45.5 & \\
\hline \multirow[t]{14}{*}{ Province of residence } & Bangui & 41 & 51.9 & 38 & 48.1 & 0.446 \\
\hline & Bambari & 1 & 50.0 & 1 & 50.0 & \\
\hline & Basse Kotto & 6 & 40.0 & 9 & 60.0 & \\
\hline & Haute Kotto & 3 & 60.0 & 2 & 40.0 & \\
\hline & Kembe & 2 & 33.3 & 4 & 66.7 & \\
\hline & Lobaye & 0 & 0.0 & 7 & 100.0 & \\
\hline & Mbomou & 3 & 75.0 & 1 & 25.0 & \\
\hline & Nana Mambere & 1 & 25.0 & 3 & 75.0 & \\
\hline & Ombela-M'poko & 27 & 51.9 & 25 & 48.1 & \\
\hline & Ouaka & 1 & 100.0 & 0 & 0.0 & \\
\hline & Ouham & 5 & 55.7 & 4 & 44.3 & \\
\hline & Ouham Pende & 5 & 50.0 & 5 & 50.0 & \\
\hline & Sangha Mbaere & 0 & 0.0 & 1 & 100.0 & \\
\hline & Vakaga & 2 & 66.7 & 1 & 33.3 & \\
\hline
\end{tabular}
senting with clinical symptoms.
Table 2 Distribution of positive results for pathogens in differential diagnosis of yellow fever according to sociodemographic characteristics in the CAR (2008-2010)

HDV is a satellite of hepatitis B virus, and infection with this virus aggravates acute and chronic liver disease. A review of the literature shows strong variations in the prevalence of this virus among Africans seropositive for $\mathrm{HbsAg}$, and the presence of this marker may constitute support for the argument that it plays a role in the development of HBsAg-associated liver diseases [26]. A study conducted in the CAR in 1989 showed that delta virus was the cause of fulminating hepatitis with severe jaundice in 124 cases [27]. In another study, however, it was much more common in patients with chronic liver disease [28].

Hepatitis $\mathrm{E}$ virus is endemic in central Africa, due mainly to poor environmental hygiene, a deteriorating health network and very poor epidemiological surveillance. Hepatitis E virus outbreaks were reported, for example, in 2002, 2004 and 2005 in Bangui [29, 30], and imported hepatitis E virus was documented in 2011, prompting implementation of the International Health Regulations (2005) in the CAR [31].

Severe malaria caused exclusively by $P$. falciparum in the CAR is also considered in people presenting with febrile jaundice, as this disease is endemic in the area. 
Table 3 Pathogens identified in samples negative for yellow fever IgM, CAR, 2008-2010

\begin{tabular}{lll}
\hline Infectious agent & No. of samples tested $^{\text {a }}$ & No. positive (\%) \\
\hline HBsAg & 162 & $32(19.8)$ \\
HEV $^{b}$ & 198 & $27(13.6)$ \\
HCVAg & 162 & $9(5.6)$ \\
P. falciparum & 198 & $4(2.0)$ \\
Anti-HD & & $17(34.0)$ \\
HEV + HBsAg & 50 & $6(3.7)$ \\
HBsAg + HCVAg & 162 & $4(2.5)$ \\
HBsAg + P. falciparum & 162 & $4(2.5)$ \\
P. falciparum + HCVAg & 162 & $3(1.9)$ \\
HCVAg + HEV & 162 & $2(1.2)$ \\
HEV + P. falciparum & 198 & $2(1.0)$ \\
HBsAg + HEV + P. falciparum & 162 & $2(1.2)$ \\
HBsAg + HEV + HCVAg & 162 & $1(0.6)$ \\
HBSAg + P. falciparum + & 162 & $1(0.6)$ \\
HCVAg & & $0(0,0)$ \\
Other pathogens &
\end{tabular}

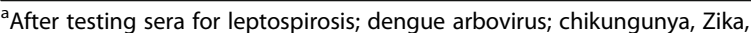
Crimean-Congo haemorrhagic fever, West Nile and Rift Valley viruses; and $P$. falciparum, sufficient quantities of serum remained for testing only a further 162 samples

${ }^{\mathrm{b}}$ Hepatitis $\mathrm{E}$ virus, tested with qPCR

${ }^{c}$ Hepatitis delta virus

dLeptospirosis; DENV; CHIK, ZIKV, CCHFV, WNV and RVFV

In severe malaria, jaundice is related to severe haemolysis, hepatocellular damage, drug toxicity or a combination [32-34]. Co-infections with these pathogens are alarming because of their potential synergy in hepatitis dysfunction. The co-existence of malaria and viral hepatitis in developing countries like the CAR may thus present a diagnostic dilemma and severe complications and delay treatment [35].

We did not identify most of the less prevalent infections, such as leptospirosis, dengue, chikungunya, Zika, Crimean-Congo haemorrhagic fever, West Nile or Rift Valley fever, despite the fact that Africa has become a hotspot for leptospirosis research by microbiologists working to differentiate the causal agents of yellow fever [36].

More than half $(51.0 \%)$ the cases of febrile jaundice had none of the studied pathogens. This was to be expected, as other differential diagnoses of fever with jaundice include community-acquired sepsis, amoebic fever, acute cholecystitis and choledocholithiasis [37].

The main limitation of this study is the relatively small number of samples selected for testing, which may therefore not adequately represent the target population. Specifically, the proportion of people with $\mathrm{HCV}$ infection in this sample would not be representative of the overall proportion in the CAR, as febrile jaundice is present in only a subset of people with newly acquired infection. Another limitation is that only samples that were negative for yellow fever were tested. Some of the samples positive for yellow fever virus might also yield positive results for other infectious pathogens [38] that have life-threatening synergistic effects.

\section{Conclusions}

This study shows that acute hepatitis virus infections are still an important problem in the CAR. It is therefore essential to scale up hepatitis $B$ vaccination and improve sanitation and environmental hygiene. Moreover, clinicians should be sensitized to the diagnostic dilemma of patients presenting with febrile jaundice. This study provides data on the prevalence of these diseases and the possibility of epidemics. Nationwide surveillance for yellow fever should be complemented by a survey of hepatitis viruses and other emerging haemorrhagic infections.

\begin{abstract}
Abbreviations
CAR: Central African Republic; CCHFV: Crimean-Congo haemorrhagic fever virus; CHIK: Chikungunya; DEN: Dengue; DENT: Dengue total; DENV: Dengue virus; ELISA: Enzyme-linked immunosorbent assay; HBsAg: Hepatitis B surface antigen; HCV: Hepatitis C virus; HDV: Hepatitis delta virus; HEV: Hepatitis E virus; IgM: Immunoglobulin M; GPCR: Quantitative polymerase chain reaction; RVFV: Rift Valley fever virus; WHO: World Health Organization; WNV: West Nile virus; ZIKV: Zika virus
\end{abstract}

\section{Acknowledgements}

We thank the Ministry of Health, health professionals in the various health facilities, the WHO Representative and nongovernmental organizations in the CAR for transporting samples to the laboratory and for diagnostic reagents. We also thank all the patients who participated in this study. We are also grateful to Professeur Elisabeth Heseltine for her support in editing this manuscript.

\section{Funding}

The Institut Pasteur de Bangui and the Ministry of Health in the CAR supported the study financially. National surveillance of yellow fever and the pathogens targeted in this analysis was funded by WHO.

\section{Availability of data and materials}

The datasets generated and analysed during the current study is not publicly available because it contains potentially identifiable information but is available from the corresponding author on reasonable request.

\section{Authors' contributions}

CLBG supervised the field activities, participated in collecting data, analysed and interpreted the data and wrote the manuscript. AM prepared the questionnaire and analysed and interpreted the data. GT contributed to writing the manuscript. XK performed the ELISA tests. UV contributed to the analysis and interpretation of the data. EN designed the study and directed it, supervised all the field activities and contributed to the analysis and interpretation of the data. All the authors participated in writing this draft and approved the final version of the manuscript for publication.

Ethics approval and consent to participate

This surveillance programme was approved by the expert committee for the yellow fever control programme of the Ministry of Health in CAR. As national surveillance is performed for transmissible diseases subject to mandatory declaration in the country (yellow fever and other haemorrhagic fevers), patient consent was not necessary.

Consent for publication

Not applicable. 


\section{Competing interests}

The authors declare that they have no competing interests.

\section{Publisher's Note}

Springer Nature remains neutral with regard to jurisdictional claims in published maps and institutional affiliations.

\section{Author details}

${ }^{1}$ Institut Pasteur of Bangui, Virology Department, PO Box 923, Bangui, Central African Republic. ${ }^{2}$ Institut Pasteur of Bangui, Epidemiology Service, PO Box 923, Bangui, Central African Republic. ${ }^{3}$ Hôpital de l'Amitié, Ministry of Public Health, Population and AIDS Control, PO Box 883, Bangui, Central African Republic.

Received: 25 April 2017 Accepted: 19 November 2017

Published online: 29 November 2017

\section{References}

1. Chung JP, Kim KW, Chi HS, Lee SI, Shin ET, Cho JH, et al. Obstructive jaundice due to compression of the common hepatic duct by right hepatic artery-a case associated with the absence of the lateral segment of the left hepatic lobe. Yonsei Med J. 1994:35(2):231-8.

2. Chang K, Yan JJ, Lee HC, Liu KH, Lee NY, Ko WC, Acute h. With or without jaundice: a predominant presentation of acute $\mathrm{Q}$ fever in southern Taiwan. J Microbiol Immunol Infect. 2004;37(2):103-8.

3. Shah S, Ali L, Sattar RA, Aziz T, Ansari T, Ara J. Malarial hepatopathy in falciparum malaria. J Coll Physicians Surg Pak. 2009;19(6):367-70.

4. L'Azou M, Succo T, Kamagate M, Ouattara A, Gilbernair E, Adjogoua E, et al. Dengue: etiology of acute febrile illness in Abidjan, cote d'Ivoire, in 2011 2012. Trans R Soc Trop Med Hyg. 2015;109(11):717-22.

5. Schindler M, Kreplak N, Acevedo L, Damis H, Marquez G, Ardaiz MC. Febrile cholestatic jaundice as an initial manifestation of Hodgkin's disease. Medicina (Buenos Aires). 2014:74(1):60-1.

6. Yesilyurt M, Kilic S, Gursoy B, Celebi B, Yerer M. Two cases of acute hepatitis associated with Q fever. Mikrobiyol Bul. 2012;46(3):480-7.

7. Taddio A, Pellegrin MC, Centenari C, Filippeschi IP, Ventura A, Maggiore G. Acute febrile cholestatic jaundice in children: keep in mind Kawasaki disease. J Pediatr Gastroenterol Nutr. 2012;55(4):380-3.

8. Juwah Al, Nlemadim A, Kaine W. Clinical presentation of severe anemia in pediatric patients with sickle cell anemia seen in Enugu, Nigeria. Am J Hematol. 2003;72(3):185-91.

9. Wolfsen HC, Bolen JW, Bowen JL, Fenster LF. Fulminant herpes hepatitis mimicking hepatic abscesses. J Clin Gastroenterol. 1993;16(1):61-4.

10. Rose HD, Lentino JR, Mavrelis PG, Rytel MW. Jaundice associated with nonhepatic Staphylococcus aureus infection. Does teichoic acid have a role in pathogenesis? Dig Dis Sci. 1982;27(11):1046-50.

11. World Health Organization: District guidelines for yellow fever surveillance (WHO/EPI/GEN/98.09) (http://www.who.int/csr/resources/publications/ yellowfev/whoepigen9809.pdf, accessed 12 June 2015).

12. Isa SE, Onyedibe Kl, Okolo MO, Abiba AE, Mafuka JS, Simji GS, et al. A 21 year-old student with fever and profound jaundice. PLoS Negl Trop Dis. 2014;8(1):e2534.

13. Rachas A, Nakoune E, Bouscaillou J, Paireau J, Selekon B, Senekian D, et al. Timeliness of yellow fever surveillance, Central African Republic. Emerg Infect Dis. 2014;20(6):1004-8.

14. World Health Organization. Yellow fever surveillance and outbreak response: revision of case definitions, October 2010. Wkly Epidemiol Rec. 2010:85:461-72.

15. Nabeth P, Cheikh DO, Lo B, Faye O, Vall IO, Niang M, et al. Crimean-Congo hemorrhagic fever, Mauritania. Emerg Infect Dis. 2004;10(12):2143-9.

16. Saluzzo JF, Anderson GW Jr, Hodgson LA, Digoutte JP, Smith JF. Antigenic and biological properties of Rift Valley fever virus isolated during the 1987 Mauritanian epidemic. Res Virol. 1989;140(2):155-64.

17. SJ W, Pal S, Ekanayake S, Greenwald D, Lara S, Raviprakash K, et al. A dryformat field-deployable quantitative reverse transcriptase-polymerase chain reaction assay for diagnosis of dengue infections. Am J Trop Med Hyg. 2008:79(4):505-10

18. Vasickova P, Kralik P, Slana I, Pavlik I. Optimisation of a triplex real time RTPCR for detection of hepatitis E virus RNA and validation on biological samples. J Virol Meth. 2012;180(1-2):38-42
19. Faye O, Diallo D, Diallo M, Weidmann M, Sall AA. Quantitative real-time PCR detection of Zika virus and evaluation with field-caught mosquitoes. Virol J. 2013;10:311.

20. Yap G, Pok KY, Lai YL, Hapuarachchi HC, Chow A, Leo YS, et al. Evaluation of chikungunya diagnostic assays: differences in sensitivity of serology assays in two independent outbreaks. PLoS Negl Trop Dis. 2010;4(7):e753.

21. Lanciotti RS, Kerst AJ, Nasci RS, Godsey MS, Mitchell CJ, Savage HM, et al. Rapid detection of West Nile virus from human clinical specimens, fieldcollected mosquitoes, and avian samples by a TaqMan reverse transcriptasePCR assay. J Clin Microbiol. 2000;38(11):4066-71.

22. Drosten C, Gottig S, Schilling S, Asper M, Panning M, Schmitz H, et al. Rapid detection and quantification of RNA of Ebola and Marburg viruses, Lassa virus, Crimean-Congo hemorrhagic fever virus, Rift Valley fever virus, dengue virus, and yellow fever virus by real-time reverse transcription-PCR. J Clin Microbiol. 2002:40(7):2323-30.

23. Pawlotsky JM, Belec L, Gresenguet $G$, Deforges $L$, Bouvier M, Duval J, et al. High prevalence of hepatitis $B, C$, and $E$ markers in young sexually active adults from the Central African Republic. J Med Virol. 1995;46(3):269-72.

24. Bekondi C, Olinger CM, Boua N, Talarmin A, Venard V, Muller CP, et al. Characterization of hepatitis B virus strains from the Central African Republic: preliminary results. Pathol Biol (Paris). 2008;56(5):310-3.

25. Komas NP, Vickos U, Hubschen JM, Bere A, Manirakiza A, Muller CP, et al. Cross-sectional study of hepatitis B virus infection in rural communities, Central African Republic. BMC Infect Dis. 2013;13:286.

26. Roingeard P, Sankale $J$, Dubois F, Diouf A, Bacha A, Mboup S, et al. Infection due to hepatitis delta virus in Africa: report from Senegal and review. Clin Infect Dis. 1992;14(2):510-4.

27. Lesbordes JL, Ravisse P, Georges AJ, Beuzit Y, Ave P, Enamra D, et al. Role of delta viruses in fulminating hepatitis in Central Africa. Ann Med Interne (Paris). 1987;138(3):199-201.

28. Andernach IE, Leiss LV, Tarnagda ZS, Tahita MC, Otegbayo JA, Forbi JC, et al. Characterization of hepatitis delta virus in sub-Saharan Africa. J Clin Microbiol. 2014:52(5):1629-36.

29. Goumba Al, Konamna X, Komas NP. Clinical and epidemiological aspects of a hepatitis E outbreak in Bangui, Central African Republic. BMC Infect Dis. 2011;11:93.

30. Escriba JM, Nakoune E, Recio C, Massamba PM, Matsika-Claquin MD Goumba C, et al. Hepatitis E, Central African Republic. Emerg Infect Dis. 2008;14(4):681-3.

31. World Health Organization: International Health Regulations (2005). Geneva; 2005

32. Abro AH, Ustadi AM, Abro HA, Abdou AS, Younis NJ, Akaila SI. Jaundice with hepatic dysfunction in P. falciparum malaria. J Coll Physicians Surg Pak. 2009:19(6):363-6.

33. Mazumder R, Mishra RK, Mazumder H, Mukherjee P. Jaundice in falciparum malaria-some prospective observations. J Indian Med Assoc. 2002;100(5): $312-4$.

34. Mishra D, Chaturvedi D, Mantan M. Typhoid fever and viral hepatitis. Indian J Pediatr. 2008;75:509-10.

35. Zaki S, Asif S, Dadge D, Shanbag P. Co-existence of viral hepatitis with malaria. J Postgrad Med. 2009;55(3):233.

36. Porterfield JS. Yellow fever in West Africa: a retrospective glance. BMJ. 1989; 299(6715):1555-7.

37. Gordon MA, Walsh AL, Chaponda M, Soko D, Mbvwinji M, Molyneux ME, et al. Bacteraemia and mortality among adult medical admissions in Malawi - predominance of non-typhi salmonellae and Streptococcus pneumoniae. Inf Secur. 2001:42(1):44-9.

38. Baba M, Logue $\mathrm{CH}$, Oderinde B, Abdulmaleek H, Williams J, Lewis J, et al. Evidence of arbovirus co-infection in suspected febrile malaria and typhoid patients in Nigeria. J Infect Dev Countries. 2013;7(1):51-9. 